\title{
Reassessment of acrylamide content in breakfast cereals. Evolution of the Spanish market from 2006 to 2018
}

\author{
M. Mesías, L. Sáez-Escudero, F.J. Morales, C. Delgado-Andrade \\ Institute of Food Science, Technology and Nutrition, ICTAN-CSIC, Madrid 28040, Spain
}

\begin{abstract}
Breakfast cereals are important contributors to acrylamide daily exposure in Western countries. Acrylamide was determined by LC-ESI-MS/MS in 60 commercial breakfast cereals marketed in Spain. The influence of the predominant cereal, protein, fibre and sugar content, as well as the presence of honey and the manufacturing process on the acrylamide levels was evaluated. The mean acrylamide content was $118 \mu \mathrm{g} / \mathrm{kg}$ (from<20 to $639 \mu \mathrm{g} / \mathrm{kg}$ ). The group of breakfast cereals formulated with kamut, spelt, and wheat reported the higher levels $(639,20 \mathrm{I}$ and $197 \mu \mathrm{g} / \mathrm{kg}$, respectively). The type of processing significantly affected the occurrence of acrylamide, being higher in puffed cereals $(167 \mu \mathrm{g} / \mathrm{kg})$ than in flaked ones $(79 \mu \mathrm{g} / \mathrm{kg})$. The majority (85\%) samples were below the benchmark level established by the EU Regulation 2017/2158. Acrylamide occurrence in breakfast cereals marketed in Spain has greatly decreased since 2006 (60\%), leading to a reduction of the contribution of breakfast cereals to the overall exposure to the population from $1.02 \mu \mathrm{g} /$ day to $0.54 \mu \mathrm{g} /$ day. Despite this progress, more efforts are needed to continue the acrylamide mitigation until levels as low as reasonably possible since no tolerable intake could be established for a carcinogenic and genotoxic compound.
\end{abstract}

KEYWORDS: breakfast cereals; acrylamide; exposure; cereal processing; consumers

\section{INTRODUCTION}

Cereal-based foodstuffs are one of the food commodities more prone to acrylamide formation due to their particular composition rich in reducing sugars and the amino acid asparagine and the use of thermal treatments above $120^{\circ} \mathrm{C}$ with low moisture content (Mottram, Wedzicha, \& Dodson, 2002; Zyzac et al., 2003). Among them, breakfast cereals comprise a huge family of products obtained by different technological processes applied to a variety of cereal crops. Manufacture of breakfast cereals usually involves extrusion (under intermediate aw and temperature over $80-95^{\circ} \mathrm{C}$ ) and drying-toasting (low aw and temperature higher than $150^{\circ} \mathrm{C}$ ). These operations promote the development of the Maillard reaction, the main chemical reaction giving rise to acrylamide (Stadler et al., 2002).

The European Food Safety Agency (EFSA) has identified acrylamide as a public health concern due to its relation with the appearance of different types of cancer, requiring continued efforts to reduce its exposure (EFSA, 2015). During the last years EFSA has maintained a high level of supervision to monitor the acrylamide levels in the processed products, urging the companies to implement effective mitigation strategies for reducing the formation of the contaminant. To achieve this objective and based on the EFSA control data between 2007 and 2012, in 20II and 2013 the European Commission adopted recommendations with indicative values for the main food sources of acrylamide (Commission Recommendation, 201I; 2013). Recently this Commission has published a regulation that sets mitigation measures for the reduction of this compound in foods, identifying new benchmark levels for a number of food categories (European Commission, 2017). The Regulation 2158/2017 compels food processors and food business operators in Europe to reduce the presence of acrylamide in their products, applying measures proportionate to the size and nature of the establishments. 
Breakfast cereals are one of the main contributors to acrylamide exposure and therefore are included among the foodstuffs regulated by the European Commission (EFSA, 2015). Throughout the last recommendations, reference levels of the compound in breakfast cereals have been decreasing from 400 to $150-300 \mu \mathrm{g} / \mathrm{kg}$, including different categories depending on the type of cereal. The last regulation fixes the benchmark levels of $150 \mu \mathrm{g} / \mathrm{kg}$ for maize, oat, spelt, barley, and rice based products and of $300 \mu \mathrm{g} / \mathrm{kg}$ for bran products and wholegrain cereals, gun puffed grain and wheat, and rye based products (European Commission, 2017). In order to prevent and reduce formation of acrylamide specifically in breakfast cereals manufacturing processes, the acrylamide toolbox recommends the choice of cereal varieties (related to the content of asparagine and reducing sugars), to control the ingredients added into the formulation and the optimization of thermal input of process. Although in other cereal-based foods the use of asparaginase is an effective mitigation strategy, it is not applied in the breakfast cereal sector. The low moisture content during their processing makes difficult the enzyme penetration into the food matrix and therefore the effectiveness of this operation (FDE, 20I3).

The breakfast cereal market is constantly evolving, looking for innovations that aim to satisfy the new consumers' demands focused on health and well-being criteria. Traditional cereals are commonly mixed or replaced by new cereals, pseudo-cereals or ingredients, offering new products which, in some cases, are gluten-free alternatives intended for people with celiac disease. Likewise, novel formulations containing spelt, quinoa, kamut or teff, allow consumers to choose those that best suit their lifestyle.

In 2006, our research group carried out the first prospective study in breakfast cereals commercialised in Spain to evaluate the magnitude of the occurrence of acrylamide in this foodstuff. An average value of 292 $\mu \mathrm{g} / \mathrm{kg}$ was reported, with specific mean levels of $207 \mu \mathrm{g} / \mathrm{kg}$ for corn, $144 \mu \mathrm{g} / \mathrm{kg}$ for rice, $382 \mu \mathrm{g} / \mathrm{kg}$ for wheat and $307 \mu \mathrm{g} / \mathrm{kg}$ for cereal mixture products (Rufián-Henares, Delgado-Andrade, \& Morales, 2006). Taking into account the current regulation and the proposed measures in recent years to control acrylamide occurrence, it is necessary to reassess the levels in breakfast cereals currently marketed in Spain. In this way, the effects of the possible implementation of mitigation strategies in the breakfast cereal sector can be analysed. Moreover, this evaluation will allow performing a new situational study about this food commodity, considering the expansion of the breakfast cereal market with new formulations.

The aim of this work was to obtain a reliable evaluation about the acrylamide levels in the Spanish breakfast cereal market in order to update the contribution of this foodstuff to the exposure to this contaminant. The impact of factors such as composition, target population or manufacturing process was assessed. Additionally, results were compared with data previously reported by our research group in 2006, in order to analyse the evolution in the acrylamide content in Spanish breakfast cereals over the last decade and the effectiveness of the mitigation strategies by the cereal industry.

\section{MATERIALS AND METHODS}

\section{I Reagents and chemicals}

Potassium hexacyanoferrate (II) trihydrate (98\%, Carrez-I) and zinc acetate dehydrate (> 99\%, Carrez-II) were obtained from Sigma (St. Louis, USA). 13C3-labelled acrylamide ( $99 \%$ isotopic purity) was obtained from Cambridge Isotope Laboratories (Andover, MA, USA). Formic acid (98\%) was from Panreac (Barcelona, Spain). Deionized water was obtained from a Milli-Q Integral 5 water purification system (Millipore, Billerica, MA, USA). Reversed-phase Oasis-HLB cartridges $(30 \mathrm{mg}, 1 \mathrm{~mL}$ ) were from Waters 
(Milford, MA, USA). Syringe filter units $(0.45 \mu \mathrm{m}$, cellulose) were purchased from Análisis Vínicos (Tomelloso, Ciudad Real, Spain). All other chemicals, solvents and reagents were of analytical grade.

\subsection{Samples}

Sixty commercial packaged breakfast cereal products from more than 20 producers were purchased from different supermarkets during February 2018. Most commercial samples and manufacturers included in the sampling are brands widely distributed throughout Europe and America. Breakfast cereals containing dried fruits, nuts or chocolate were excluded from this study to avoid bias during data interpretation. Nutritional composition of samples is included in Table I as declared by the manufacturers. Samples were classified according to several variables: cereal (a predominant cereal or a mixture of them), type of grain (refined or wholegrain), protein content (below or above $7.5 \% \mathrm{w} / \mathrm{w}$ ), fibre content (below or above $5 \% \mathrm{w} / \mathrm{w}$ ), sugar content (below or above $20 \% \mathrm{w} / \mathrm{w}$ ), addition of honey to the recipe (yes or no), target consumer (children or general population) and type of processing (flaked or puffed). Samples were mixed and thinly ground to assure a homogeneous mixture, placed in a polyethylene container, sealed under vacuum and stored at $4^{\circ} \mathrm{C}$ until analyses.

\subsection{LC-ESI-MS/MS determination of acrylamide}

Sample extraction and clean up were based on the method described by Mesías and Morales (2015) and ISO:EN:16618:2015 with minor modifications. Ground sample was weighed and mixed with water in polypropylene centrifugal tubes. Mixture was spiked with $\left[{ }^{13} \mathrm{C}_{3}\right]$-acrylamide methanolic solution as internal standard and later homogenized (Ultra Turrax, IKA, Mod-TIO basic, Germany) for 10 min. Afterwards, sample was treated with Carrez I (I5 g potassium ferrocianide/ $100 \mathrm{~mL}$ water) and Carrez II (30 g zinc acetate/ $100 \mathrm{~mL}$ water) solutions and centrifuged $(9,000 \mathrm{~g}$ for $10 \mathrm{~min})$ at $4^{\circ} \mathrm{C}$. Samples were cleaned up by using Oasis-HLB cartridges and filtered through a $0.45 \mu \mathrm{m}$ filter into an amberlite LC-MS/MS vial.

Sample extracts and calibration standards were analysed on an Agilent 1200 liquid chromatograph coupled to an Agilent Triple Quadrupole MS detector (Agilent Technologies, Palo Alto, CA, USA). Analytical separation was achieved with an Inertsil ODS-3 column $(250 \times 4.6 \mathrm{~mm}, 5 \mu \mathrm{m}$; GL Sciences Inc., Tokyo, Japan) at $30^{\circ} \mathrm{C}$. Isocratic elution was achieved with a mobile phase of formic acid in water $(0.2 \mathrm{~mL} / 100 \mathrm{~mL})$ at a flow rate of $0.4 \mathrm{~mL} / \mathrm{min}$. The injection volume was $10 \mu \mathrm{L}$. Electrospray ionization in the positive ionization mode was used. Under these chromatographic conditions, acrylamide eluted at $6.1 \mathrm{~min}$. The needle was set at $1.0 \mathrm{kV}$. Nitrogen was used as nebulizer gas $(12.0 \mathrm{~L} / \mathrm{min})$ and the source temperature was set at $350{ }^{\circ} \mathrm{C}$. Signals at $\mathrm{m} / \mathrm{z} 72.1-\mathrm{m} / \mathrm{z} 55.1$ and $\mathrm{m} / \mathrm{z} 75.1-\mathrm{m} / \mathrm{z} 58.1$ were isolated for acrylamide and $\left[{ }^{13} \mathrm{C}_{3}\right]$-acrylamide, respectively. For the transitions $\mathrm{m} / \mathrm{z} 72.1>\mathrm{m} / \mathrm{z} 55.1$ and $\mathrm{m} / \mathrm{z} 75.1>\mathrm{m} / \mathrm{z} 58$. I the fragmentation was set at $76 \mathrm{~V}$ and the collision energy at $8 \mathrm{~V}$. Masses were recorded using multiple reactions monitoring (MRM). For quantitation the signals at $\mathrm{m} / \mathrm{z} 75.1$ and 78.1 were used, while signals at $\mathrm{m} / \mathrm{z} 58.1$ and 55.1 served for qualification. The accuracy of the results was recently demonstrated for potato crisps in four proficiency tests launched by the Food Analysis Performance Assessment Scheme (FAPAS) program, yielding a z-score of 0.2 (Test 3065, May-June 2016), - 0.2 (Test 307I, Feb-March 2017), -0.3 (Test 3080, Feb-March 20I8) and 0.0 (Test 3085, Sep-Oct 2018). Precision (reproducibility) was lower than 10\% and recovery between 84 and 109\%. The limits of quantitation and detection were set at 20 and $6 \mu \mathrm{g} / \mathrm{kg}$, respectively. Analyses were performed in duplicate and results were expressed as $\mu \mathrm{g} / \mathrm{kg}$ of product.

\subsection{Food consumption data}

Dietary exposure to acrylamide from the whole breakfast cereal category as well as grouped according to the different types of cereals was estimated combining the data of total per capita consumption of breakfast 
cereals ( $1.7 \mathrm{~kg} /$ person/year) established by the Spanish Ministry of Agriculture, Food and Environment (MAPAMA, 2016) and the acrylamide content detected in samples.

\subsection{Statistical Analysis}

Statistical analyses were performed using SPSS version 23 (SPSS, Chicago, IL). Data were expressed as mean \pm standard deviation (SD). One-way ANOVA followed by least significant differences (LSD) test or Student's t-test, according to needs, were used to identify the overall significance of differences. All statistical parameters were evaluated at $p<0.05$ significance level.

\section{RESULTS AND DISCUSSION}

\section{I Nutritional Composition of Breakfast Cereals}

Table I depicts the nutritional composition of breakfast cereals as declared by the manufacturer. That information has only a descriptive purpose and is compiled in order to better understand the formation of acrylamide depending on the composition of the products in the raw matter. Regardless of the type of cereal, breakfast cereals exhibited close values for energy, ranging between 316 and $465 \mathrm{kcal} / 100 \mathrm{~g}$. Protein ranged from 4.7 to $19.0 \mathrm{~g} / \mathrm{l} 00 \mathrm{~g}$, carbohydrates from 37.8 to $88.0 \mathrm{~g} / \mathrm{l} 00 \mathrm{~g}$, sugars from $<0.5$ to $49.0 \mathrm{~g} / \mathrm{l} 00 \mathrm{~g}$ and fibre from 2.0 to $33.1 \mathrm{~g} / 100 \mathrm{~g}$. Excepting two samples with a higher fat content ( 18.6 and $16.0 \%$ for muesli and crunchy organic cereal mixture, respectively), the rest of the breakfast cereals showed a total fat content below $10 \%$. Only thirteen of the sixty samples contained honey in concentrations lower than 5 $\mathrm{g} / \mathrm{l} 00 \mathrm{~g}$. Based on the differences observed in composition and as we considered in our previous sampling (Rufián-Henares et al., 2006), samples were grouped according to the predominant cereal, type of grain (refined or wholegrain), protein content (above or below 7.5\%), fibre content (above or below 5\%), sugar content (above or below 20\%) and the presence/absence of honey in its formulation. Additionally, the target consumers (children or general population) and the manufacturing process (flaked or puffed) were considered as interesting factors to establish comparisons in the dataset (Table I).

\subsection{Acrylamide levels in breakfast cereals. Effect of type of cereal in the formulation}

Sixty commercial breakfast cereals from more than 20 producers were analysed for acrylamide content. Individual values are depicted in Fig. I. Acrylamide ranged from lower than $20 \mu g / \mathrm{kg}$ (LOQ) to $639 \mu \mathrm{g} / \mathrm{kg}$, with an average value of $118 \mu \mathrm{g} / \mathrm{kg}$ and a median value of $64 \mu \mathrm{g} / \mathrm{kg}$. Two samples showed acrylamide levels below the LOQ. It is worthy to mention that these values are close to those reported by EFSA (2015) for breakfast cereals from different European countries (mean value: $113 \mu \mathrm{g} / \mathrm{kg}$; median value: $67 \mu \mathrm{g} / \mathrm{kg}$ ). Our results also are in agreement with the ranges reported in the recent study by Kafouris et al. (2018) for breakfast cereals commercialised in Cyprus (10-520 $\mathrm{gg} / \mathrm{kg}$ ), and close to those reported by Capei, Pettini, Lo Nostro, and Pesa Vento (2015) in breakfast cereals available in the Italian market (< 10-810 $\mu g / \mathrm{kg})$.

It is well-known that asparagine and reducing sugars are the main precursors for acrylamide formation in food matrices. Among them, asparagine is considered the critical component leading to acrylamide formation in cereal-derived products (Granby et al., 2008). The protein content and amino acid composition differs within cereal varieties and, therefore, in the absence of other ingredients, the type of cereal used in the formulation of the breakfast cereals will influence drastically the acrylamide formation (FoodDrinkEurope, 2014). In the present study, the maximum level of acrylamide was detected in the breakfast cereal made up of kamut $(639 \mu \mathrm{g} / \mathrm{kg})$, followed by those essentially based in spelt (mean: $20 \mathrm{I}$ $\mu \mathrm{g} / \mathrm{kg}$ ) and wheat (mean: $197 \mu \mathrm{g} / \mathrm{kg}$ ) (Fig. 2A). Przygodzka et al. (2015) analysed asparagine content in wheat, spelt and rye flours for bread making with a 70\% extraction rate, showing levels of 78, 173 and $322 \mathrm{mg} / \mathrm{kg}$, respectively. Glucose content was undetectable in any cases. These flours were used for baking bread at 
$200^{\circ} \mathrm{C}$ during $35 \mathrm{~min}$ and acrylamide content was subsequently measured. The following growing order was depicted: rye bread > spelt bread > wheat bread. In the present study, similar acrylamide values were observed for spelt and wheat-based breakfast cereals. However, the category termed spelt-based only included one sample composed exclusively of spelt (organic spelt puffed, Table I), which showed a great value of acrylamide $(482 \mu \mathrm{g} / \mathrm{kg})$. In the other cases, spelt was mixed with barley or rice leading to a dilution effect in the precursors and then to decreased acrylamide content in the final product $(47$ and $72 \mu \mathrm{\mu g} / \mathrm{kg}$, respectively). In addition, only one sample of breakfast cereal rye-based was included and, adversely to the statement of Przygodzka et al. (20I5), it presented a low acrylamide content (26 $\mu \mathrm{g} / \mathrm{kg})$ (Fig. 2A), below the concentration detected in spelt and wheat-based samples.

Breakfast cereals with barley, teff or quinoa as predominant grain exhibited low amounts of acrylamide (26, $6 \mathrm{I}$ and $44 \mu \mathrm{g} / \mathrm{kg}$, respectively; Fig. 2A). These categories were also represented only by one sample. In contrast, corn, oat and rice-based breakfast cereals were well-represented in this study $(n=14,8$ and 6$)$. The acrylamide concentration was very similar between them, with mean values of 64,70 and $74 \mu \mathrm{g} / \mathrm{kg}$, respectively (Fig. 2A). It is known that corn and rice are grains with a low presence of asparagine (European Commission, 2017), a fact supporting the moderate acrylamide formation in these breakfast cereals. In parallel, the category of cereal-mixture, in which the presence of corn and rice flours was predominant in the formulation, also exhibited a low mean concentration of the contaminant $(75 \mu \mathrm{g} / \mathrm{kg}$; Fig. 2A).

In accordance with the European Regulation (European Commission, 2017), the benchmark levels of acrylamide presence in breakfast cereals depend on the cereal used in the formulation. The grain present in the largest quantity determines the category. A benchmark level of $300 \mu \mathrm{g} / \mathrm{kg}$ has been set for bran products, whole grain cereals and gun puffed grain (group I) and as well as for wheat and rye based products (group 2). For maize, oat, spelt, barley, and rice based products (group 3), the benchmark level established in the regulation is $150 \mu \mathrm{g} / \mathrm{kg}$ (Fig. I). Samples of the present study were grouped according to this classification (Fig. 2B). Thirty-nine of the samples belonged to groups I and 2 and among them $20 \%$ was above the recommended value (eight samples, all of them from group I) (Fig. I). Seven of these samples were products that have been extruded to obtain a puffed presentation, what supposes a technological process with additional heat charge. In this sense, the composition of the foodstuffs and the different processing conditions often affecting temperature and moisture content may contribute to the generation of process contaminants and thus to the great differences found in the final product (Cheng, Sun, Chou, \& Yeh, 2012; Stadler \& Studer, 2017). The remaining twenty-one samples in our study were catalogued within the group 3 and only one of them surpassed the reference, so that $95 \%$ of breakfast cereals grouped in this section complied with the regulation. Globally, we concluded that $85 \%$ of the breakfast cereals sampled was below their corresponding benchmark level.

\subsection{Factors affecting acrylamide occurrence in breakfast cereals}

The formulation of the breakfast cereal is a key factor influencing acrylamide formation since it definitively affects the concentration of precursors (FoodDrinkEurope, 2014). Based on a previous study by our research group (Rufián-Henares et al., 2006), besides the predominant cereal, samples were grouped according to six additional factors: type of grain (refined or wholegrain), protein content (below or above $7.5 \%$ ), fibre content (below or above $5 \%$ ), sugar content (below or above $20 \%$ ), honey presence in the recipe, target consumer (children or general population) and type of processing (flaked or puffed) (Table 2).

In the European monitoring dataset (2010-2013), mean acrylamide levels were higher in breakfast cereals based on bran and wholegrains $(21 \mathrm{I} \mathrm{\mu g} / \mathrm{kg})$ than in those made from wheat and rye $(170 \mu \mathrm{g} / \mathrm{kg})$ or based on 
corn, oats, spelt, barley and rice (102 $\mathrm{gg} / \mathrm{kg}$ ) (EFSA, 2015). Our study performed in 2006 already anticipated that breakfast cereals with a high dietary fibre content presented significantly higher acrylamide levels. However, data from the present sampling indicated that the level of protein and fibre did not influence the acrylamide concentration in the samples. This fact could point to an improvement in the ingredients or in the technological processes applied by the breakfast cereal industry throughout the last decade. Manufacturers are adopting newer technologies and equipment to enhance different aspects. For example, innovative enzyme technologies and bioprocessing coupled with high-pressure processing technology are being used to improve the overall safety, quality, and nutritional traits of oats-based foods (Hüttner, Dal Bello, Poutanen \& Arendt, 2009; Sibakov et al., 2015). Regardless the fibre content in the product, the inclusion of wholegrains significantly increased the acrylamide content in breakfast cereals compared with those formulated with refined grains ( 152 vs. $70 \mu g / k g$ ).

A high sugar content in the marketed breakfast cereals is the consequence of adding this ingredient to the formulation. Acrylamide values did not significantly differ due to the presence of a high level of sugars in the final product (> 20\%). In general, in the modern breakfast cereal industry, after mixing the cereal flours, they are submitted to a cooking-extrusion and shaping step, usually within the same instrument. Then, the puffed or flaked product is transported to a coating device where sugar syrup is sprayed. At this moment other ingredients such as cocoa or honey can be applied or even vitamins and minerals if a fortification strategy is pursued to optimize the nutritional value. Afterwards, coated products are discharged onto a belt dryer to reach targeted levels of moisture for an optimised texture. Hot coated cereals are cooled to prevent water condensation and led to the packaging step (Fast, 200I). Based on the acrylamide Toolbox (FoodDrinkEurope, 2014), the addition of honey, glucose, fructose and other reducing sugars during the coating step and not before avoids the excessive darkening and acrylamide formation. This fact also would explain that the presence of honey or sugar content higher than $20 \%$ did not influence the levels of the contaminant in breakfast cereals (Table 2).

The samples were also grouped according to the target consumer to whom they were addressed, since many of them contained dietary or health claims in their packaging. In the study carried out in 2006 we stated that the type of target consumer (infant or adult) affected the acrylamide presence in the product. However, in the current sampling, in which the category general is comparable to the former adult, acrylamide level did not differ between products intended for children or for general population. The discrepancy between both studies could be due to the total number of samples considered to be of special interest for the adult/general population in each of them ( $n=5$ for 2006 and $n=16$ for 2018), which is actually a reflection of how the breakfast cereal market has evolved in the last decade.

The formation of acrylamide during the processing of cereals is closely related to the combination of moisture content and temperature/cooking time (FoodDrinkEurope, 2014). The factor that critically influenced the acrylamide formation in the present study was the manufacturing process. As we found out in 2006, puffed samples exhibited significantly greater acrylamide concentration $(167 \mu g / k g)$ than flaked cereals $(79 \mu \mathrm{g} / \mathrm{kg})$ (Table 2). The puffing process involves more extreme conditions than the flaking one since puffed cereals are always obtained by extrusion. In the classic method to produce flakes, ground grains are boiled $\left(80-95^{\circ} \mathrm{C}\right)$, dried $\left(220^{\circ} \mathrm{C}\right)$ to decrease moisture content, laminated, toasted $\left(160-200^{\circ} \mathrm{C}\right)$ and coated, if appropriate (Guy, 2002). However, in the modern extrusion method, cereal flours are directly cooked in the extruder at $140-180^{\circ} \mathrm{C}$, dried and shaped thanks to the sudden decompression at the exit of the extruder. Then, they are toasted at temperatures that can reach $330^{\circ} \mathrm{C}$. Finally, they can be fortified and 
coated like in the traditional process (Fast, 200I). Differences in moisture, temperatures and residence times help to explain the significantly higher acrylamide content detected in puffed breakfast cereals.

\subsection{Evaluation of acrylamide exposure from Spanish commercialized breakfast cereals}

In June 2015, EFSA concluded that the presence of acrylamide in foods potentially increases the risk of developing certain types of cancer in all age groups (EFSA, 2015). Due to this uncertainty regarding the human health risk, exposure to acrylamide is a public health concern and a priority for the National Food Safety Authorities. The exposure to acrylamide from breakfast cereals for the adult Spanish population was calculated on the basis of the data of total per capita consumption of this foodstuff established by the Spanish Ministry of Agriculture, Food and Environment (1.7 kg/person/year) (MAPAMA, 2016) and the acrylamide content in the studied breakfast cereals (Table 3). When different predominant grains were considered, exposure was calculated assuming that all the breakfast cereals consumed in a year came from the same group. As expected due to the acrylamide levels found in the different groups of cereals, kamutderived breakfast cereal represented the highest exposition level, whereas barley, rye, teff and quinoa-based ones supposed low exposition rates to the contaminant. Apart from the case of kamut, which was an exceptional situation probably due to the analysis of only one sample, acrylamide exposure through the consumption of wheat and spelt-based products was the most important (mean values $0.9 \mathrm{I}$ and $0.92 \mu \mathrm{g} /$ day, respectively). Corn, oat, rice-based breakfast cereals and those made up of a mixture of grains depicted intermediate exposure data (mean values ranging from 0.29 to $0.35 \mu \mathrm{g} /$ day). Taking into account the mean acrylamide content in the global sampling, the exposure to the contaminant ranged from 0.05 to $2.94 \mu \mathrm{g} / \mathrm{day}$, with a mean value of $0.54 \mu \mathrm{g} /$ day. This figure is half of the estimation performed in our study in 2006 ( 1.02 $\mu \mathrm{g} /$ day), when the data was calculated with the Spanish breakfast cereal consumption at that moment ( 1.28 $\mathrm{kg} /$ person/year) (MAPAMA, 2006). The current exposure data is also lower than that reported by the Swedish National Food Administration at the beginning of the acrylamide alarm (SNFA, 2002), calculated as $0.75 \mu \mathrm{g} /$ day for breakfast cereals.

\subsection{Evolution of the Spanish breakfast cereal market in terms of acrylamide occurrence from 2006 to 2018}

Taking into account the progress of the technological processes in the food industry during the last decade and the efforts that the international organisms have dedicated to emphasise the importance of introducing acrylamide mitigation strategies, we understand that the reassessment of acrylamide occurrence in Spanish breakfast cereals was needed and relevant. Fig. 3A compares the mean acrylamide level determined in the sampling carried out by our research group in 2006 (Rufián-Henares et al., 2006) with the reassessed value in 2018. A significant decrease of around $60 \%$ in the mean value can be observed. Fig. 3B depicts data according to the cereal type. To be consistent with the categories studied in 2006, only wheat, corn, rice and multi-cereal based breakfast cereal have been included in this comparison. A clear contribution of the four categories in the decline is observed but specially attributed to corn and rice-based ones as well as to those made up of cereal mixtures. The Scientific report of EFSA about the update on acrylamide levels in food from monitoring years 2007-2010 already described a reduction in the levels of acrylamide in breakfast cereals, both for the maximum levels (from 1600 to $1290 \mu \mathrm{g} / \mathrm{kg}$ ) and for the mean values (from 149 to 91 $\mu \mathrm{g} / \mathrm{kg}$ ) (EFSA, 2012). Although Biedermann et al. (2010) reported an increase in the acrylamide content of cereals and muesli commercialised in Switzerland during 2007-2008-2009, more updated data by Claeys et al. (2016) established the drop in different foodstuffs from the Belgian market between 2002 and 2013 including ready-to-eat cereals. The decline in the acrylamide levels through the years demonstrates the 
effectiveness of mitigation strategies in the breakfast cereal industry based on the control of agronomical factors, recipe and processing (European Commission, 20I7; FoodDrinkEurope, 20I4).

\section{CONCLUSIONS}

This work compiles the occurrence of acrylamide in commercial breakfast cereals of the current Spanish market not only with a descriptive purpose but also to monitor the evolution of acrylamide presence in this food category from 2006 to 2018. Eighty-five percent of analysed samples were below the benchmark levels marked in the last European regulation. As previously stated in 2006 by our research team, the manufacturing process significantly influenced the concentration of the contaminant, with the puffed forms being more prone to its accumulation. Based on 2006-2018 comparison, acrylamide occurrence in the breakfast cereal market has experienced an important decline (60\%), probably as a consequence of improved technological processes, higher quality ingredients and the application of mitigation strategies. According to these results, estimation of acrylamide exposure from breakfast cereal has dropped $50 \%$ in Spain during that period. Despite the progress, more efforts are needed to mitigate acrylamide in this and other foodstuffs to reach levels as low as reasonably possible since no tolerable intake could be established for this compound due to its carcinogenicity and genotoxicity.

\section{CONFLICTS OF INTEREST}

The authors declare that they have no conflict of interest.

\section{ACKNOWLEDGMENTS}

This work was partially supported by the Comunidad of Madrid and European funding from FSE and FEDER programs (project S20I8/BAA-4393, AVANSECAL-II-CM) and by the project CSIC-20I770I025 (Spanish National Research Council). Authors thank Ms. I. Alvarez and B. Díaz for their technical assistance.

\section{REFERENCES}

Biedermann, M., Grundbo, F., Fiselier, K., Biedermann, S., Bürgi, C., \& Grob, K. (20I0). Acrylamide monitoring in Switzerland, 2007-2009: Results and conclusions. Food Additives \& Contaminants, 27, I3521362.

Capei, R., Pettini, L., Lo Nostro, A., \& Pesa Vento, G. (20I5). Occurrence of acrylamide in breakfast cereals and biscuits available in Italy. Journal of Preventive Medicine and Hygiene, 56, EI 90-EI 95.

Cheng, W. C., Sun, D. C., Chou, S. S., \& Yeh, A. I. (20I2). Acrylamide content distribution and possible alternative ingredients for snack foods. Journal of Food Protection, 75, 2158-2162.

Claeys, W., De Meulenaer, B., Huyghebaert, A., Scippo, M. L., Hoet, P., \& Matthys, C. (2016). Reassessment of the acrylamide risk: Belgium as a case-study. Food Control, 59, 628-635.

Commission Recommendation (20II). Investigations into the levels of acrylamide in food. Official Journal of the European Union. http://ec.europa.eu/food/food/chemicalsafety/contaminants/recommendation_I00I20II_acrylamide_food_e n.pdf.

Commission Recommendation (2013). Investigations into the levels of acrylamide in food. Official Journal of the European Union L $30 \mathrm{I} / \mathrm{I} 5$. 
EFSA (European Food Safety Agency) (2015). Scientific opinion on acrylamide in food. EFSA Journal, 13, 4104. Available http://www.efsa.europa.eu/sites/default/files/scientific_output/files/main_documents/4104.pdf.

EFSA (European Food Safety Authority) (2012). Update on acrylamide levels in food from monitoring years 2007 to 2010. https://efsa.onlinelibrary.wiley.com/doi/epdf//0.2903/j.efsa.2012.2938, Accessed date: 7 November 2018.

European Commission (2017). Commission Regulation (EU) 2017/2I58 of 20 November 2017 establishing mitigation measures and benchmark levels for the reduction of the presence of acrylamide in food. Official Journal of the European Union, L304, 24-44.

Fast, R. (200I). Breakfast cereals. In G. Owens (Ed.). Cereals processing technology (pp. 158-172). Cambridge, UK: Woodhead Publishing.

FoodDrinkEurope, F. D. E. (2014). http://fooddrinkeurope.eu/uploads/publications_documents/AcrylamideToolbox_2013.pdf.

Granby, K., Nielsen, N. J., Hedegaard, R. V., Christensen, T., Kann, M., \& Skibsted, L. H. (2008). Acrylamideasparagine relationship in baked/toasted wheat and rye breads. Food Additives \& Contaminants, 25, 92I929.

Guy, R. (2002). Extrusión de los alimentos: Tecnología y aplicaciones (pp. |3|-160). España: Acribia Editorial (part II. Hüttner, E. K., Dal Bello, F., Poutanen, K., \& Arendt, E. K. (2009). Fundamental evaluation of the impact of high hydrostatic pressure on oat batters. Journal of Cereal Science, 49, 363-370.

Kafouris, D., Stavroulakis, G., Christofidou, M., lakovou, X., Christou, E., Paikousis, L., et al. (20/8). Determination of acrylamide in food using a UPLC-MS/MS method: Results of the official control and dietary exposure assessment in Cyprus. Food Additives \& Contaminants: Part A, 35, 1928-1939.

MAPAMA (Ministerio de Agricultura, Alimentación y Medio Ambiente) (2006). Informe del consumo de alimentos en España 2016. https://www.mapa.gob.es/app/consumoen-hogares/resultadol.asp.

MAPAMA (Ministerio de Agricultura, Alimentación y Medio Ambiente) (2016). Informe del consumo de $\begin{array}{llll}\text { alimentos } & \text { en } & 2016 .\end{array}$ http://www.mapama.gob.es/es/alimentacion/temas/informe_del_consumo_de_alimentos_en_espana_2016_w ebvf_tcm30-386079.pdf.

Mesías, M., \& Morales, F. J. (2015). Acrylamide in commercial potato crisps from Spanish market: Trends from 2004 to 2014 and assessment of the dietary exposure. Food and Chemical Toxicology, 8I, 104-1I0.

Mottram, D. S., Wedzicha, B. L., \& Dodson, A. T. (2002). Acrylamide is formed in the Maillard reaction. Nature, 4I9, 448-449.

Przygodzka, M., Piskula, M. K., Kukurová, K., Ciesarová, Z., Bednarikova, A., \& Zielinski, H. (2015). Factor influencing acrylamide formation in rye, wheat and spelt breads. Journal of Cereal Science, 65, 96-102.

Rufián-Henares, J. A., Delgado-Andrade, C., \& Morales, F. J. (200). Relationship between acrylamide and thermal-processing indexes in commercial breakfast cereals: A survey of Spanish breakfast cereals. Molecular Nutrition \& Food Research, 50, 756-762. 
Sibakov, J. K., Kirjoranta, S. J., Alam, S. A., Kokkonen, H., Jurvelin, J. S., Jouppila, K., et al. (2015). Effect of oat bran fractions on extrudates made of defatted oats. Food and Bioprocess Technology, 8, 445-458.

SNFA (Swedish National Food Administration) (2002). Acrylamide in foodstuffs, consumption and intake. Uppsala: National Food Administration. June 6, 2002. Available www.slv.se.

Stadler, R. H., Blank, I., Varga, N., Robert, F., Hau, J., Guy, P. A., et al. (2002). Acrylamide from Maillard reaction products. Nature, 419, 449-450.

Stadler, R. H., \& Studer, A. (20I7). Acrylamide formation mechanisms. In V. Gökmen (Ed.). Acrylamide in food. Analysis, content and potential health effects (PP. I-17). London, UK: Academic Press.

Zyzac, D. V., Sanders, R. A., Stojanovic, M., Tallmadge, D. H., Eberhart, B. L., Ewald, D. K., et al. (2003). Acrylamide formation mechanisms in heated foods. Journal of Agricultural and Food Chemistry, 5I, 47824787. 


\section{FIGURES AND TABLES}

Table I. Nutritional composition of breakfast cereals per $100 \mathrm{~g}$ of sample according to the information provided by the manufacturer and classification by type of grain (refined/wholegrain), target consumer (children/general population) and manufacturing process (flaked/puffed)

\begin{tabular}{|c|c|c|c|c|c|c|c|c|c|c|}
\hline Sample & $\begin{array}{r}\text { Energy } \\
\text { (Kcal) }\end{array}$ & $\begin{array}{r}\text { Protein } \\
\text { (g) }\end{array}$ & $\begin{array}{r}\text { Carbohydrates } \\
\text { (g) }\end{array}$ & $\begin{array}{r}\text { Sugars } \\
(\mathrm{g})\end{array}$ & $\begin{array}{r}\text { Total fat } \\
(\mathrm{g})\end{array}$ & $\begin{array}{r}\text { Fibre } \\
(\mathrm{g})\end{array}$ & $\begin{array}{r}\text { Honey } \\
\text { (g) }\end{array}$ & $\begin{array}{r}\text { Refined/ } \\
\text { wholegrain }\end{array}$ & $\begin{array}{r}\text { Target } \\
\text { consumer }\end{array}$ & $\begin{array}{r}\text { Manufacturing } \\
\text { process }\end{array}$ \\
\hline \multicolumn{11}{|l|}{ Wheat based } \\
\hline Cereal flakes with oats & 367 & 9.4 & 74.8 & 10.8 & 1.7 & 7.5 & - & Refined & General & Flaked \\
\hline Fibresticks I & 334 & 14.0 & 48.0 & 18.0 & 3.5 & 27.0 & - & Wholegrain & General & Puffed \\
\hline Fibre sticks 2 & 333 & 15.0 & 45.0 & 13.0 & 3.6 & 31.0 & - & Wholegrain & General & Puffed \\
\hline Fibre sticks 3 & 321 & 14.0 & 42.0 & 22.0 & 3.5 & 32.0 & - & Wholegrain & General & Puffed \\
\hline Fibre sticks 4 & 316 & 15.3 & 37.8 & 18.4 & 4.2 & 33.1 & - & Wholegrain & General & Puffed \\
\hline Fibre sticks 5 & 318 & 14.0 & 44.0 & 23.0 & 3.5 & 28.0 & - & Wholegrain & General & Puffed \\
\hline Protein bars & 360 & 19.0 & 62.0 & 4.8 & 1.9 & 9.6 & - & Refined & General & Flaked \\
\hline Wheat bars & 362 & 12.0 & 69.0 & 4.4 & 2.0 & 10.0 & - & Wholegrain & General & Flaked \\
\hline Wheat flakes with oat I & 359 & 12.0 & 63.0 & 14.0 & 3.2 & 15.0 & - & Wholegrain & General & Flaked \\
\hline Wheat flakes with oat 2 & 371 & 10.6 & 72.0 & 13.8 & 2.4 & 9.8 & - & Wholegrain & General & Flaked \\
\hline Wheat puffed with honey & 397 & 6.6 & 83.0 & 49.0 & 3.5 & 4.1 & 4.0 & Refined & Children & Puffed \\
\hline Wheat puffed with honey 2 & 399 & 7.8 & 81.0 & 41.0 & 3.8 & 4.6 & 4.0 & Wholegrain & Children & Puffed \\
\hline Wheat puffed with honey 3 & 388 & 7.0 & 85.0 & 40.0 & 1.3 & 4.0 & 2.0 & Wholegrain & Children & Puffed \\
\hline Wheat puffed with honey 4 & 382 & 6.0 & 84.0 & 43.0 & 1.5 & 4.0 & 1.0 & Wholegrain & Children & Puffed \\
\hline Wheat puffed with honey 5 & 393 & 8.2 & 81.0 & 34.0 & 2.9 & 5.1 & 1.0 & Wholegrain & Children & Puffed \\
\hline Wheat puffed with honey 6 & 432 & 4.7 & 84.8 & 45.2 & 7.8 & n.a. & 0.2 & Wholegrain & General & Puffed \\
\hline \multicolumn{11}{|l|}{ Corn based } \\
\hline Corn flakes I & 375 & 4.5 & 87.0 & 37.0 & 0.6 & 2.0 & - & Refined & Children & Flaked \\
\hline Corn flakes 2 & 378 & 7.0 & 84.0 & 8.0 & 0.9 & 3.0 & - & Refined & General & Flaked \\
\hline Corn flakes 3 & 378 & 6.3 & 84.0 & 7.1 & 1.1 & n.a. & - & Refined & General & Flaked \\
\hline Corn flakes 4 & 385 & 8.5 & 83.4 & 5.7 & 1.2 & 3.4 & - & Refined & General & Flaked \\
\hline
\end{tabular}




\begin{tabular}{|c|c|c|c|c|c|c|c|c|c|c|}
\hline Corn flakes 5 & 377 & 8.5 & 81.6 & 2.7 & 1.1 & 3.5 & - & Refined & General & Flaked \\
\hline Corn flakes gluten-free I & 371 & 8.0 & 80.0 & 4.2 & 1.0 & 5.0 & - & Refined & General & Flaked \\
\hline Corn flakes gluten-free 2 & 371 & 8.0 & 80.0 & 4.0 & 1.0 & 5.0 & - & Refined & General & Flaked \\
\hline Corn flakes gluten-free 3 & 386 & 9.2 & 80.0 & 1.3 & 2.5 & 3.6 & - & Refined & General & Flaked \\
\hline Corn flakes sugar-free & 371 & 8.0 & 80.0 & $<0.5$ & 1.0 & 5.0 & - & Refined & General & Flaked \\
\hline Corn flakes sugary I & 380 & 6.5 & 85.1 & 24.4 & 0.9 & n.a. & - & Refined & Children & Flaked \\
\hline Corn flakes sugary 2 & 382 & 5.0 & 88.0 & 35.7 & 0.5 & 2.8 & - & Refined & Children & Flaked \\
\hline Corn pops with honey I & 380 & 5.4 & 85.0 & 28.0 & 1.1 & 4.0 & 2.0 & Wholegrain & Children & Puffed \\
\hline Corn pops with honey 2 & 381 & 6.2 & 86.0 & 27.0 & 0.9 & 2.1 & 3.5 & Wholegrain & Children & Puffed \\
\hline Corn puffed with honey & 391 & 6.5 & 88.0 & 25.0 & 1.0 & n.a. & 3.5 & Refined & Children & Puffed \\
\hline \multicolumn{11}{|l|}{ Oat based } \\
\hline Oat flakes gluten-free I & 354 & 14.7 & 58.1 & 1.7 & 4.9 & 9.1 & - & Refined & General & Flaked \\
\hline Oat flakes gluten-free 2 & 375 & 14.0 & 59.0 & 0.7 & 7.0 & 10.0 & - & Refined & General & Flaked \\
\hline Organic oat flakes I & 350 & 11.6 & 56.6 & 1.2 & 5.3 & 14.7 & - & Wholegrain & General & Flaked \\
\hline Organic oat flakes 2 & 378 & 12.0 & 60.0 & 2.0 & 8.0 & 9.1 & - & Refined & General & Flaked \\
\hline Granola with honey & 410 & 8.9 & 68.7 & 22.9 & 9.6 & 6.4 & 2.0 & Wholegrain & General & Flaked \\
\hline Muesli & 465 & 9.9 & 61.0 & 18.4 & 18.6 & 9.9 & - & Refined & General & Flaked \\
\hline Oat flakes & 361 & 14.0 & 56.0 & 1.2 & 6.7 & 11.0 & - & Refined & General & Flaked \\
\hline Oat bran & 368 & II.I & 78.6 & 9.8 & 5.2 & 19.0 & - & Wholegrain & General & Puffed \\
\hline \multicolumn{11}{|l|}{ Rice based } \\
\hline Rice flakes & 376 & 7.4 & 82.0 & 18.0 & 0.7 & 5.8 & - & Refined & General & Flaked \\
\hline Rice and whole wheat flakes & 372 & 13.0 & 77.0 & 17.0 & 1.1 & 2.7 & - & Wholegrain & General & Flaked \\
\hline Cereal flakes with whole wheat & 375 & 9.0 & 79.0 & 15.0 & 1.5 & 4.5 & - & Wholegrain & General & Flaked \\
\hline Rice puffed I & 384 & 7.0 & 85.0 & 8.0 & 1.5 & 1.0 & - & Wholegrain & Children & Puffed \\
\hline Rice puffed 2 & 374 & 7.3 & 78.0 & 0.8 & 2.9 & 3.3 & - & Wholegrain & General & Puffed \\
\hline Integral rice puffed with organic agave & 369 & 6.3 & 85.2 & 26.4 & 0.7 & 1.9 & - & Wholegrain & General & Puffed \\
\hline \multicolumn{11}{|l|}{ Spelt based } \\
\hline Crunchy organic cereal mixture & 440 & 9.3 & 62.0 & 18.0 & 16.0 & 5.5 & - & Refined & General & Flaked \\
\hline Spelt flakes & 359 & 13.0 & 68.1 & 11.0 & 2.3 & 7.8 & - & Refined & General & Flaked \\
\hline Organic spelt puffed & 375 & 13.0 & 72.0 & 1.2 & 2.5 & 6.5 & - & Wholegrain & General & Puffed \\
\hline
\end{tabular}




\begin{tabular}{|c|c|c|c|c|c|c|c|c|c|c|}
\hline \multicolumn{11}{|l|}{ Barley based } \\
\hline Organic barley flakes & 334 & 10.6 & 63.3 & 2.0 & 2.1 & 9.8 & - & Refined & General & Flaked \\
\hline \multicolumn{11}{|l|}{ Rye based } \\
\hline Organic rye flakes & 323 & 9.5 & 60.7 & 0.9 & 1.7 & 13.2 & - & Refined & General & Flaked \\
\hline \multicolumn{11}{|l|}{ Kamut based } \\
\hline Kamut puffed & 365 & 16.0 & 70.0 & 0.9 & 2.0 & n.a. & - & Wholegrain & General & Puffed \\
\hline \multicolumn{11}{|l|}{ Teff based } \\
\hline Organic teff flakes & 297 & 11.7 & 55.3 & n.a. & 1.8 & 26.2 & - & Refined & General & Flaked \\
\hline \multicolumn{11}{|l|}{ Quinoa based } \\
\hline Organic quinoa real & 357 & 5.0 & 80.3 & 2.8 & 0.9 & 3.7 & - & Wholegrain & General & Puffed \\
\hline \multicolumn{11}{|l|}{ Cereal mixture } \\
\hline Cereal rings with honey & 375 & 8.4 & 75.1 & 24.4 & 2.9 & 7.4 & 3.9 & Wholegrain & Children & Puffed \\
\hline Corn and wheat toasted cereals I & 379 & 6.5 & 81.0 & 25.0 & 2.0 & 5.4 & 1.0 & Wholegrain & Children & Puffed \\
\hline Corn and wheat toasted cereals 2 & 385 & 7.0 & 79.7 & 24.8 & 3.2 & 4.7 & - & Wholegrain & General & Puffed \\
\hline Corn balls with honey & 357 & 5.6 & 80.0 & 30.0 & 1.2 & 2.0 & 5.0 & Wholegrain & Children & Puffed \\
\hline Flakes 5 organic cereals & 349 & 10.5 & 63.7 & 0.9 & 3.5 & 10.1 & - & Refined & General & Flaked \\
\hline Fruit rings & 391 & 8.0 & 80.0 & 21.0 & 3.5 & 3.5 & - & Wholegrain & Children & Puffed \\
\hline Muesli & 342 & 9.5 & 61.0 & 4.2 & 4.0 & 12.0 & - & Refined & General & Flaked \\
\hline Wheat and rice flakes sugar-free & 364 & 9.6 & 76.0 & 1.3 & 1.7 & 7.2 & - & Wholegrain & General & Flaked \\
\hline
\end{tabular}

n.a. indicates not available data. Hypens indicate absence of honey in the formulation 
Table 2. Average acrylamide content in cereal samples grouped according to different factors.

\begin{tabular}{lcc}
\hline \multicolumn{1}{c}{ FACTOR } & $\begin{array}{c}\text { Acrylamide } \\
(\mu \mathrm{g} / \mathrm{kg})\end{array}$ & No. of samples \\
\hline $\begin{array}{c}\text { Type of grain } \\
\text { Refined }\end{array}$ & $70 \pm 66 \mathrm{a}$ & 29 \\
Wholegrain & $152 \pm 156 \mathrm{~b}$ & 32 \\
Protein content & & \\
$<7.5 \%$ & $114 \pm 114 \mathrm{a}$ & 20 \\
$>7.5 \%$ & $119 \pm 139 \mathrm{a}$ & 40
\end{tabular}

Fibre content

$\begin{array}{lll}<5 \% & 135 \pm 155 a & 26 \\ >5 \% & 104 \pm 109 a & 34\end{array}$

Sugar content

$\begin{array}{lll}<20 \% & 106 \pm 129 a & 39 \\ >20 \% & 138 \pm 132 a & 21\end{array}$

Presence of honey

$\begin{array}{lll}\text { No } & 104 \pm 123 a & 47 \\ \text { Yes } & 165 \pm 148 a & 13\end{array}$

Target consumer

Children

$111 \pm 126 \mathrm{a} \quad 16$

General population

$136 \pm 142 \mathrm{a}$

44

Manufacturing process

$\begin{array}{ccc}\text { Flaked } & 79 \pm 6 \mathrm{a} & 34 \\ \text { Puffed } & 167 \pm 17 \mathrm{~b} & 26\end{array}$

Analyses were performed in duplicate. Data are means \pm S.D. Different letters within a factor indicate statistically significant differences $(p<0.05)$. 
Table 3. Daily acrylamide exposure from the global sampling for the different types of breakfast cereals.

\begin{tabular}{lrrr}
\hline \multirow{2}{*}{ Predominant cereal } & \multicolumn{3}{c}{ Acrylamide exposure (ug/day) } \\
& Mean \pm SD & Min & Max \\
\hline Wheat & $0.91 \pm 0.57$ & 0.13 & 1.76 \\
Corn & $0.29 \pm 0.18$ & 0.12 & 0.72 \\
Oat & $0.32 \pm 0.38$ & 0.05 & 1.19 \\
Rice & $0.34 \pm 0.12$ & 0.22 & 0.54 \\
Spelt & 0.12 & 0.12 & 0.12 \\
Barley & 0.12 & 0.12 & 0.12 \\
Rye & 2.94 & 2.94 & 2.94 \\
Kamut & 0.28 & 0.28 & 0.28 \\
Teff & 0.20 & 0.20 & 0.20 \\
Quinoa & 0.22 & 2.22 \\
Mixture & $0.35 \pm 0.46$ & 0.05 & 1.44 \\
Mean value & $\mathbf{0 . 5 4} \pm \mathbf{0 . 4 6}$ & $\mathbf{0 . 0 5}$ & $\mathbf{2 . 9 4}$ \\
\hline
\end{tabular}


Figure I. Bar graph of acrylamide content in breakfast cereals. Dotted line indicate benchmark levels established by the European Commission (2017) according to the predominant cereal in the formulation ( $150 \mu \mathrm{g} / \mathrm{kg}$ for maize, oat, spelt, barley and rice based products and of $300 \mu \mathrm{g} / \mathrm{kg}$ for bran products and whole grain cereals, gun puffed grain and wheat and rye based products).

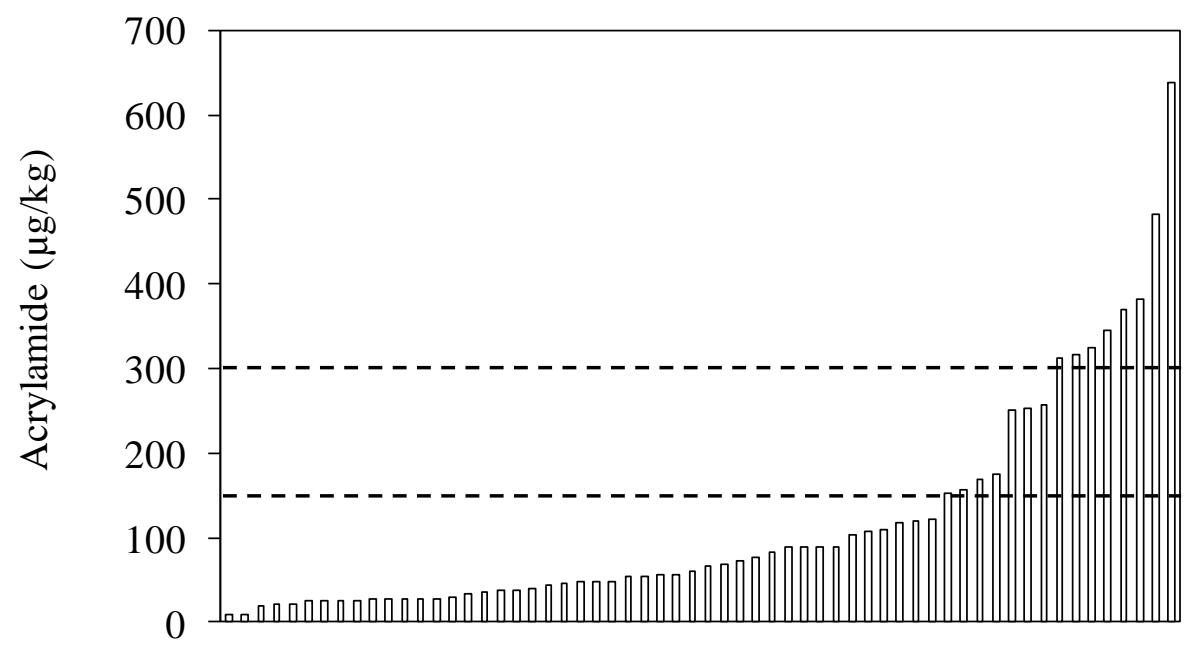

Breakfast samples 
Figure 2. Acrylamide content in breakfast cereals (A) grouped according to the predominant cereal and (B) grouped according to the classification indicated in the European Regulation: whole grain cereals and gun puffed grain (group I); wheat and rye based products (group 2); maize, oat, spelt, barley and rice-based products (group 3).

(A)

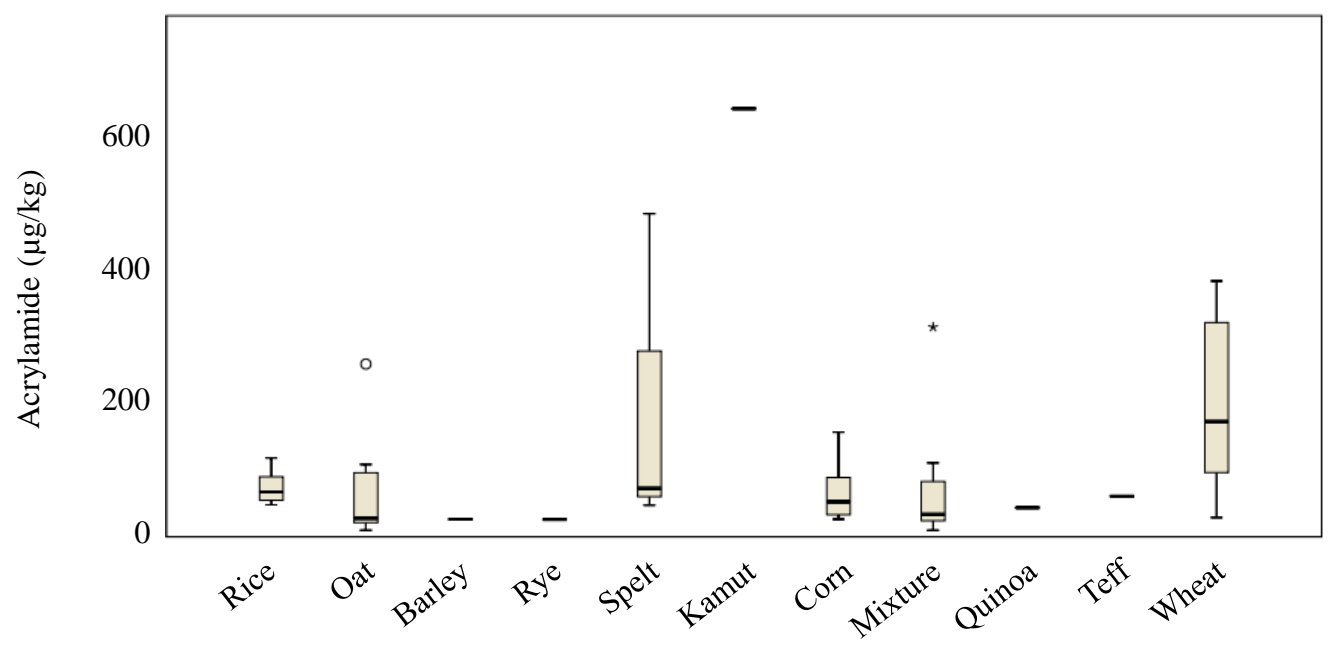

(B)

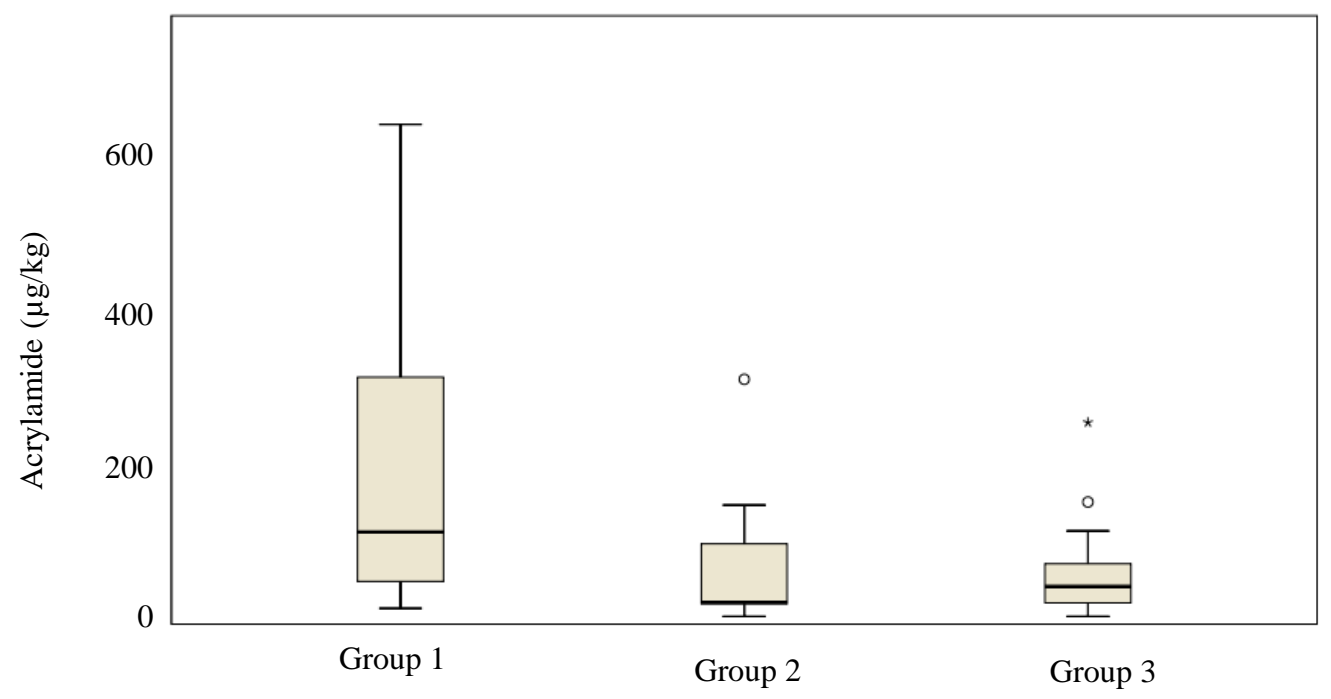


Figure 3. Comparison between acrylamide content in breakfast cereals in 2016 vs. 2018. (A) Box-andwhisker plot of global acrylamide content in breakfast cereal sampled in 2006 vs. 2018. Different letters indicate significant differences between years $(p<0.05)$. (B) Comparison of the acrylamide content in breakfast cereals grouped according to the predominant cereal in 2006 vs. 2018. Different letters within a cereal indicate significant differences between years $(p<0.05)$.

(A)

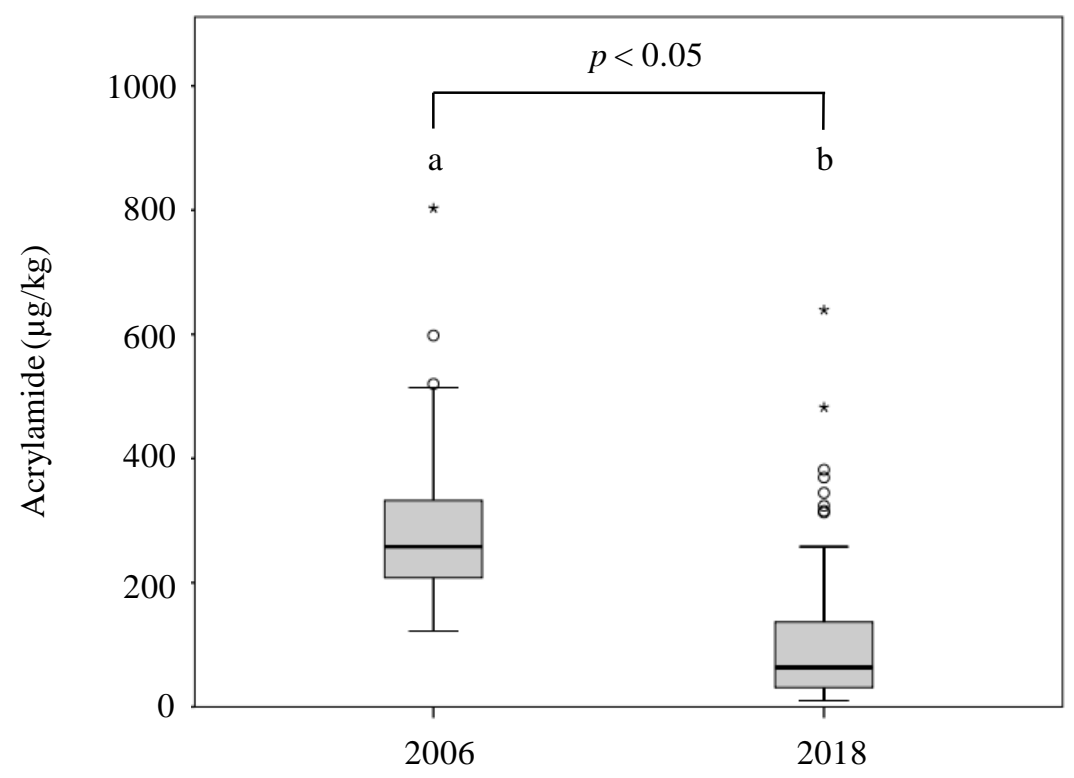

(B)

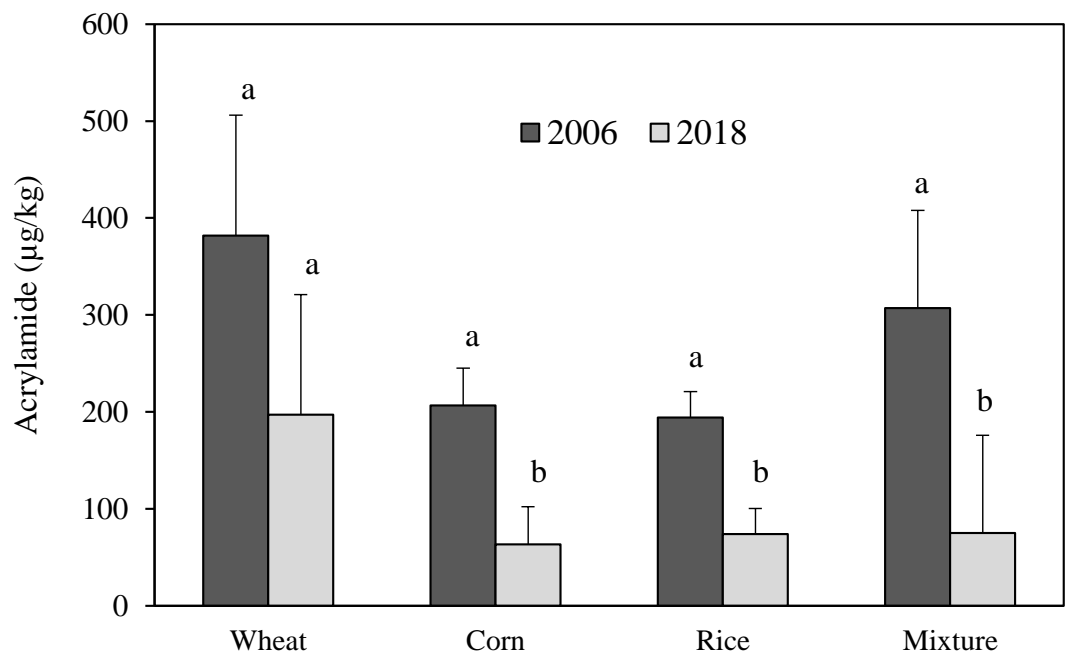

